Agropedology 2016, 26 (01), 40-46

\title{
Influence of Weather and Growth Parameters on Yield of Pigeon pea in an Alfisol of Karnataka
}

\author{
H. S. Shivaramu", M. B. Rajegowda, D.V. Soumya and L.N. Lakshmi
}

University of Agricultural Sciences, GKVK, Bengaluru- 560065

\begin{abstract}
In field trials for six years, the influence of weather parameters on pigeon pea was studied in an Alfisol of Bengaluru, Karnataka. Pooled analysis revealed that for delay in sowing by each day, the normal sowing month from June resulted in decreased yield of pigeon pea by $11.13 \mathrm{~kg} \mathrm{ha}^{-1}$, thus indicating the importance of early and timely sowing to get the advantage of higher rainfall, rainy days (RD), length of growing period (LGP in days), growing degree days (GDD) and leaf area duration (LAD in days). Among the above RD, LGP, GDD, LAD were found to have influenced the yield of pigeon pea significantly. For achieving maximum yield, the optimum values of the above parameters obtained from the fitted quadratic curves, were 90 RD, 2600 GDD and 300 LAD during the cropping period. Among the 10 multiple linear regression (MLR) models established, model $\mathrm{V}$ was found to be the most reliable in judging the yield potential of pigeon pea.
\end{abstract}

Keywords: Alfisols, climatic suitability, pigeon pea, regression models and weather parameter

\section{Introduction}

Pigeon pea [Cajanus cajan ( L.) Millsp.] is an important legume of the semi-arid tropics, grown predominantly as rainfed crop in Alfisol and Vertisols of India. It is considered as a soil ameliorant due to its deep roots which breaks plough pans, prevents soil erosion due to its extensive ground coverage of the canopy, besides nitrogen fixation and addition of biomass back to the soil through leaf fall. Assessment of climatic suitability to pigeon pea goes a long way in (i) defining agrometeorology for the crop and (ii) quantifying the limits of weather parameters to achieve the potential yield. Therefore to establish crop weather relationship, long term trials of pigeon pea were carried out in an Alfisol and weather suitability models were worked out.

\section{Materials and Methods}

Field studies on the influence of weather parameters on pigeon pea were conducted with three

*Corresponding Author Email: bng.aicrpam@gmail.com replications (Randomized Block Design) consisting of 27 treatments on spacing, variety and date of sowing for six years (2009 - 14) in GKVK farm, Bengaluru during the rainy season (from July-December). The experimental site is situated at $13^{\circ} 05^{\prime} \mathrm{N}$ latitude, $77^{\circ} 34^{\prime} \mathrm{E}$ longitude and at $924 \mathrm{~m}$. above mean sea level. The area receives around $928 \mathrm{~mm}$ of rainfall in two peaks one in May and another in September (bimodal type).

The difference in moisture holding capacity $(\mathrm{w} / \mathrm{w})$ at 33 and $1500 \mathrm{kPa}$ was multiplied by bulk density and soil depth to calculate the total plant available water holding capacity of the soil. The length of growing period was calculated following the FAO model (Higgins and Kassam 1981). However, to calculate the LGP after the cessation of rains, the actual stored soil moisture (PAWC) in each soil unit was used instead of the assumed $100 \mathrm{~mm}$ in the FAO model. The crop was raised as per the package of cultivation practices recommended for the agro-climatic zone (University of Agricultural Sciences 2012). The seed yield $\left(\mathrm{kg} \mathrm{ha}^{-1}\right)$ was calculated from the sun-dried grain weights of 
harvested net plots of $4.5 \mathrm{~m} \mathrm{X} 4.5 \mathrm{~m}$.

Correlation matrix was worked out to study the relationship of the soil-site parameters among themselves and on crop yield. In order to find the optimum range of any given soil parameter $(\mathrm{x})$ for obtaining maximum crop yield (y), a quadratic equation $\left(\mathrm{y}=\mathrm{a}+\mathrm{bx}+\mathrm{cx}^{2}\right)$ was fitted. Further, the statistical relationships between all the soil-site characteristics $\left(\mathrm{x}_{1}\right.$ to $\left.\mathrm{x}_{\mathrm{n}}\right)$ and the seed yield were established by fitting multiple linear regression (MLR) equations $(y=a+$ $\left.\mathrm{b}_{1} \mathrm{x}_{1}+\mathrm{b}_{2} \mathrm{x}_{2}+\ldots \ldots \ldots+\mathrm{b}_{\mathrm{n}} \mathrm{x}_{\mathrm{n}}\right)$. The $\mathrm{R}^{2}$ value obtained was tested at or below $5 \%$ level of significance. Using the step-down regression analysis by least square technique, the less important soil parameters were dropped one after another and the MLR models with seed yield were developed keeping the remaining important soil site parameters. Among the number of models so developed, the better models were chosen based on the criteria suggested by Barrie et al. (1986).

\section{Results and Discussion}

Pooled analysis of the data (Table 1) for understanding the effect of sowing time, varieties and spacing revealed that early sowing in June enhanced the yield of pigeon pea across all the varieties and spacings. Higher yield could be achieved mainly due to the advantage of higher LGP and GDD requirement in case of early sown crop compared to the late sown crop. Delay in sowing by each day from June to August resulted in decrease in yield by $11.13 \mathrm{~kg}$ $\mathrm{ha}^{-1}$, thus indicating the importance of early and timely sowing of pigeon pea under rainfed situations. Increased spacing and reduced population significantly reduced the yield, particularly, in early sown crop. The recently released BRG varieties out yielded the national check (TTB-7), irrespective of the sowing windows and population implying the climate resilient characteristics of the BRG series.

It was observed that among the seven weather parameters and two growth parameters (Table 2) three weather parameters and one growth parameter viz., RD, LGP, GDD and LAD had significant correlation with seed yield of pigeon pea. Pigeon pea being a long duration crop, yield had a strong positive correlation with moisture availability period defined by LGP. The relationship further indicates that LGP alone contributes $24 \%$ of the yield variation. RD also had a strong positive correlation with seed yield of pigeon pea. From the curvilinear relationship between yield and RD, optimum Rainy day requirement was worked out to be 90 rainy days (Fig.1). The third important weather parameter in the order was GDD showing relationship of quadratic nature and explaining $20 \%$ of seed yield variation $\left(\mathrm{R}^{2}=0.199\right)$. From among the growth parameters, a significant quadratic relationship between LAD and seed yield of pigeon pea was observed explaining 17\% yield variation while total dry matter (TDM) could explain 19\% of variation in yield. Accordingly, the optimum values of LAD were worked out to be 300 days (Fig. 2) and $85 \mathrm{~g} /$ plant of total dry matter. 


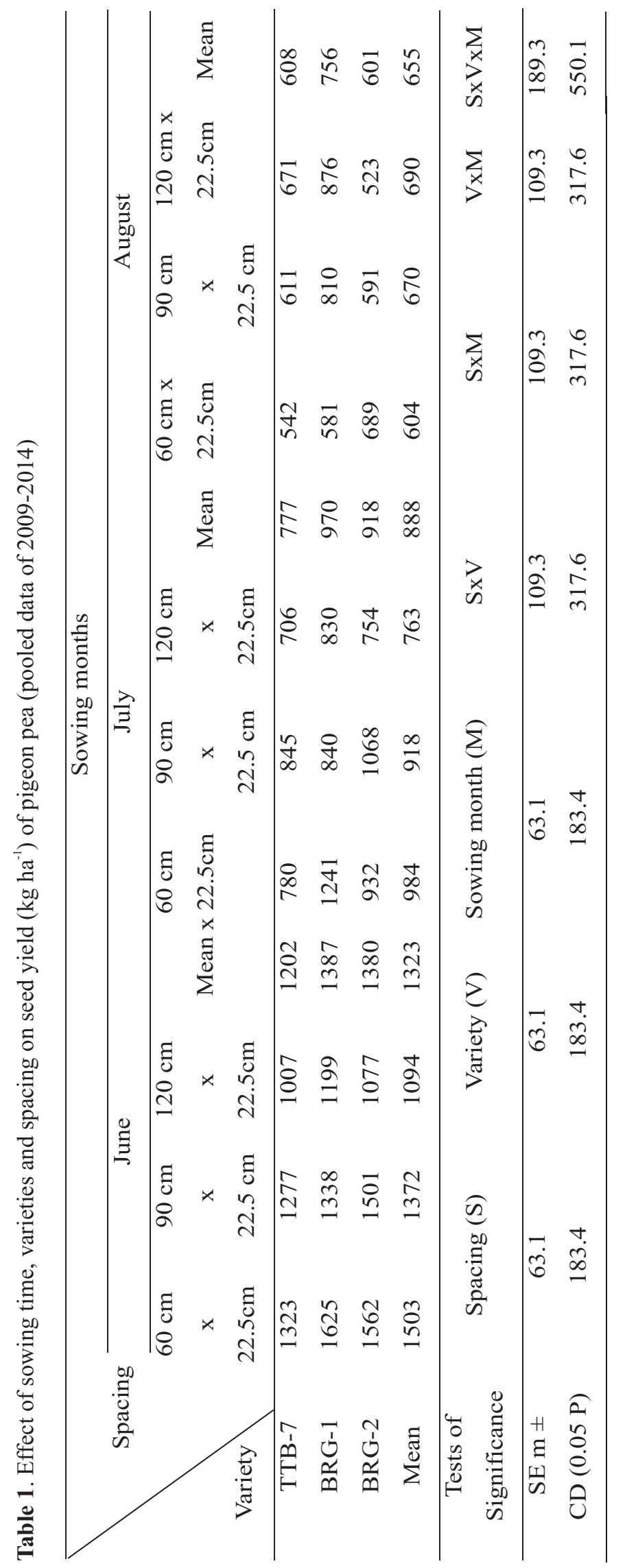




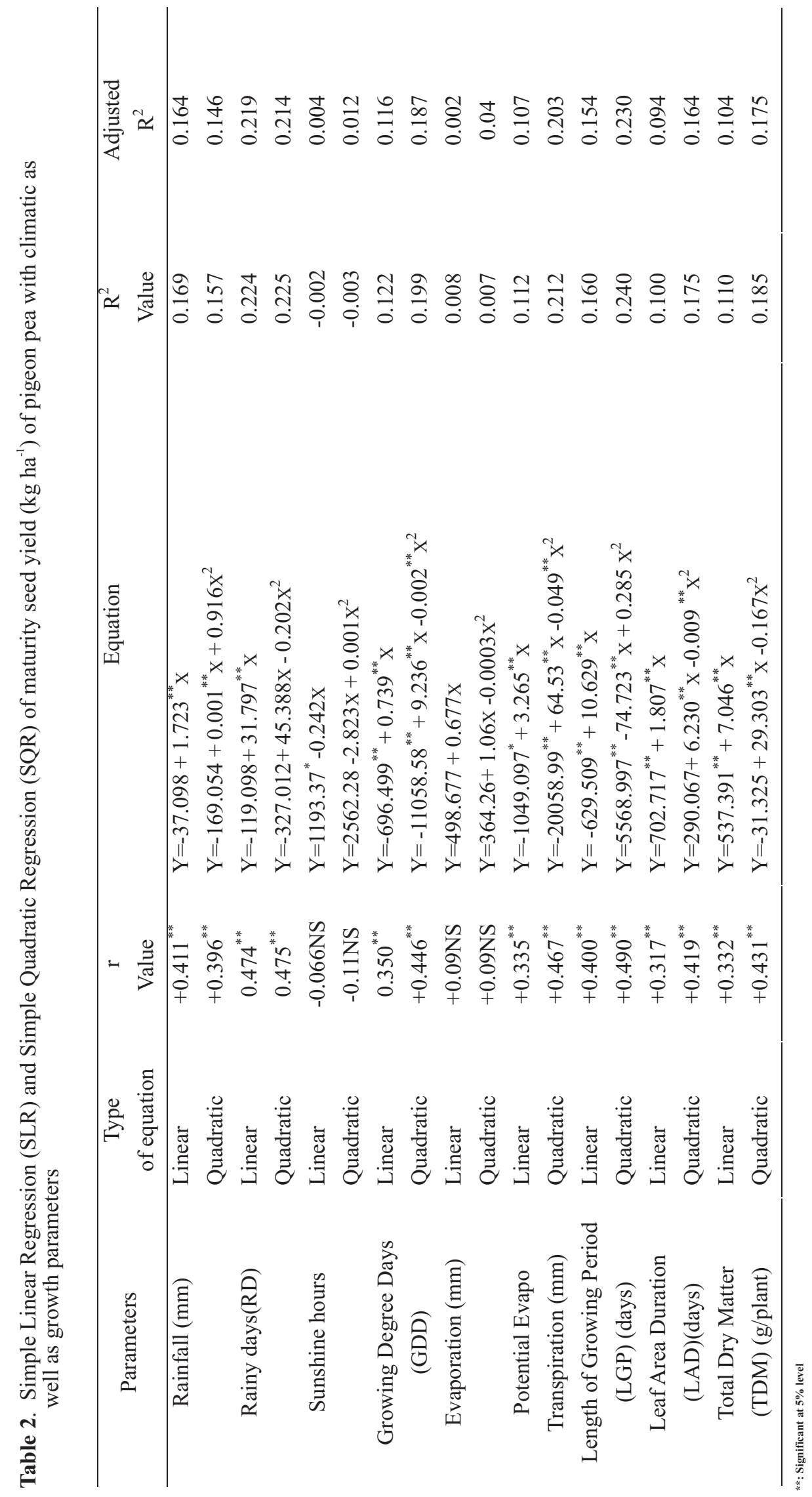




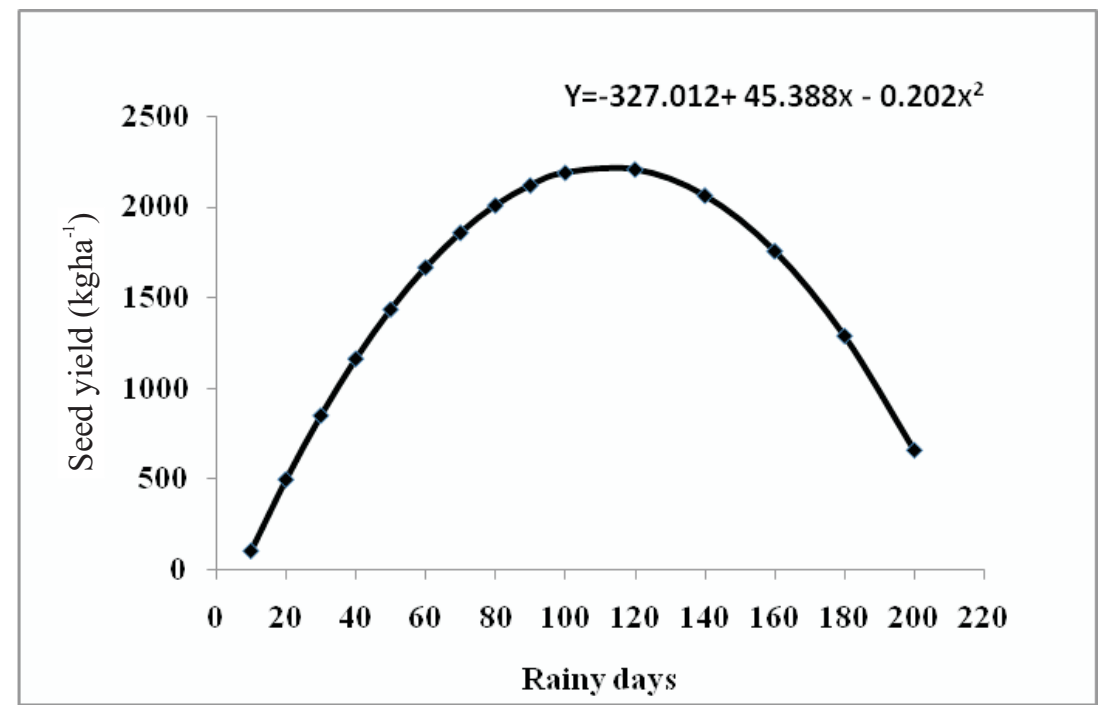

Fig. 1 Quadratic relationship between rainy days and seed yield of pigeon pea over the years in alfisols

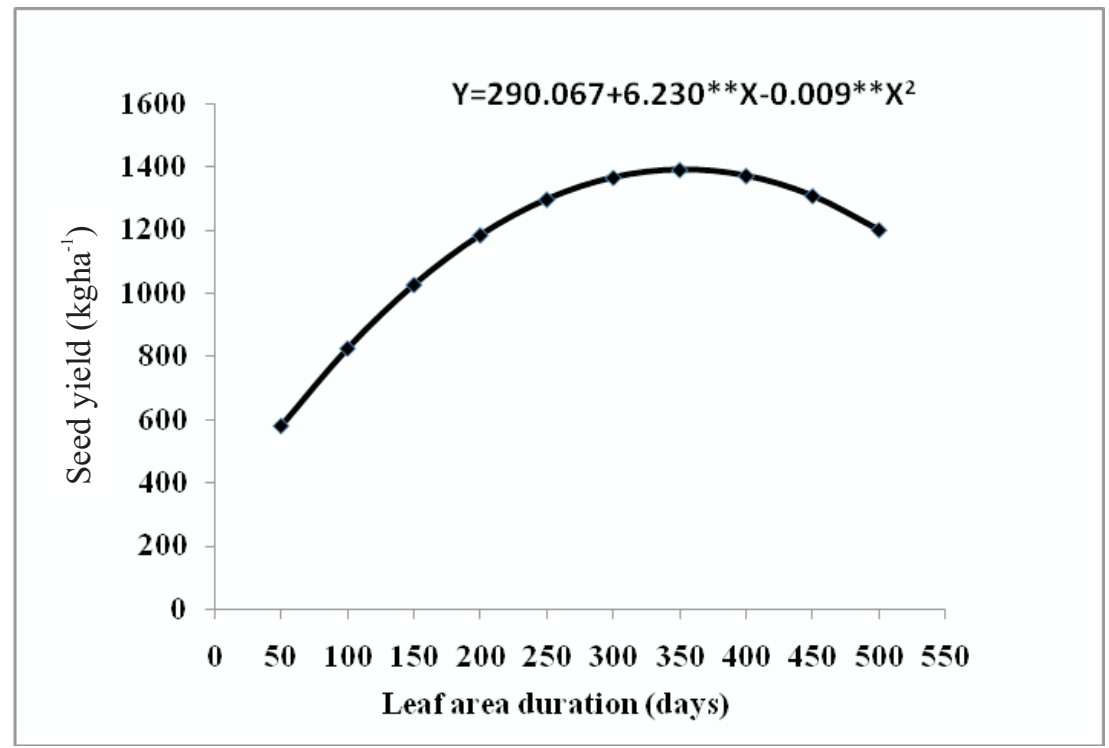

Fig. 2 Quadratic relationship between leaf area duration and seed yield of pigeon pea over the years in Alfisols

However, the accumulated sunshine in the range of 800 to $1500 \mathrm{hrs}$ was found non-significant in influencing the yield $\left(r=0.07^{\mathrm{NS}}\right)$, might be due to its nature of long duration and abundance of sunshine hours in the region. The results are in conformity with previous year's results of Bangalore (AICRPAM 2013). From the correlation matrix, LGP being closely related with not only rainfall distribution but also with available moisture holding capacity of the soil, influenced the seed yield of pigeon pea significantly (Shivaramu et al. 1997). Therefore, instead of looking at the individual effects of any parameters, the overall interaction of different non-collinear parameters on grain yield seemed to be appropriate (Shivaramu 2012) and hence 10 MLR equations were worked out. The significant $R^{2}$ values of these MLR equations ranged from 0.48 in model number I (Table 3 ), when nine weather parameters were regressed, to 0.32 in model number $X$, involving only two significant weather parameters viz., vainy days and LGP. Among these 10 models, as per the criteria set out by Barrie et al. (1986), model V $\left(\mathrm{R}^{2}=0.442^{* *}\right)$, model VII $\left(\mathrm{R}^{2}=0.362 * *\right)$ and model IX $\left(\mathrm{R}^{2}=0.359^{* *}\right)$ were found to be the better one. However, one can use any of these models for judging the suitability of a land depending on the information generated on weather parameters however bearing the risk of associated standard errors. 


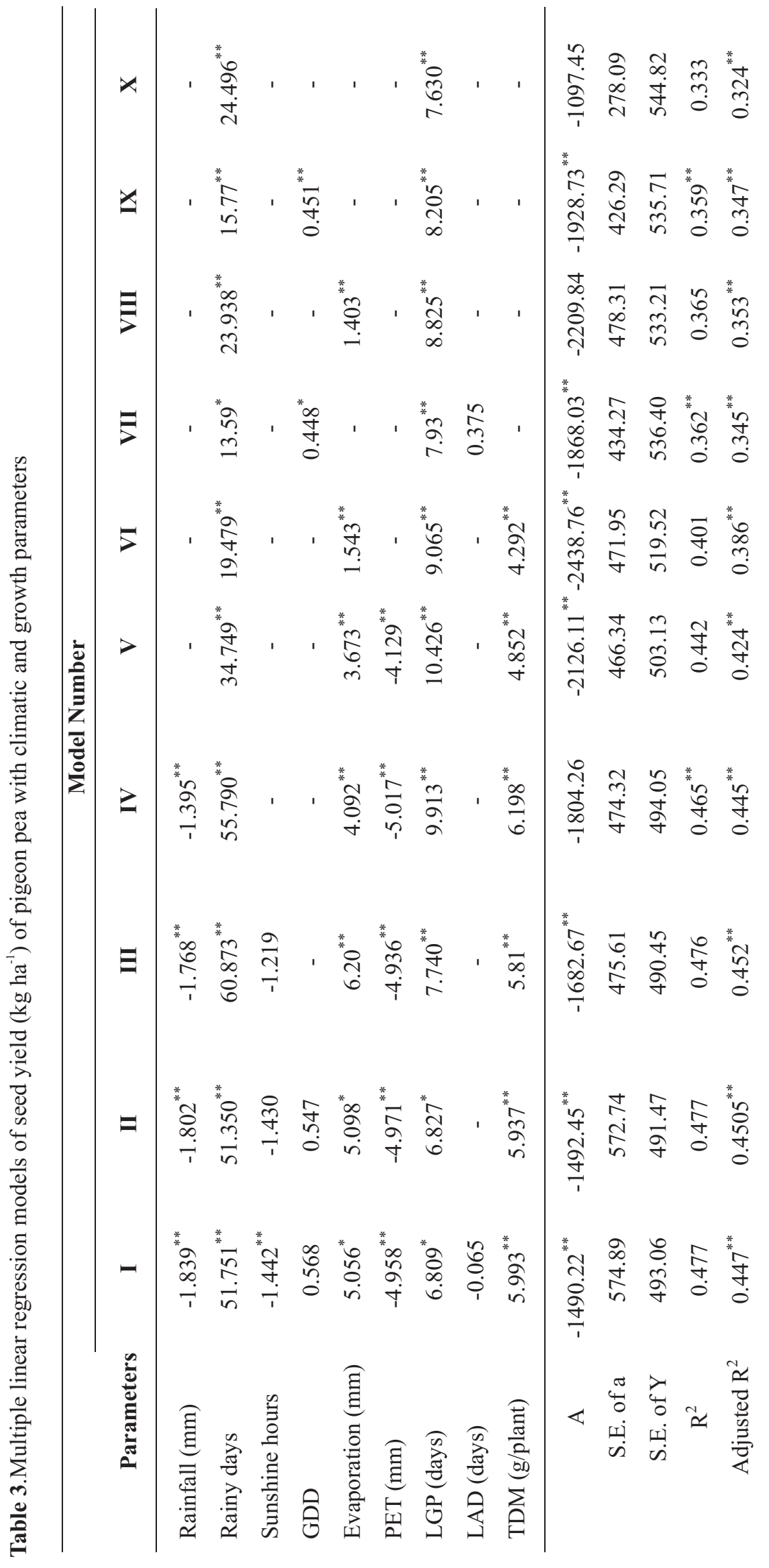


Sys et al. (1993) attempted to establish the crop requirements by setting the suitability classes and the range of limits of climate, landscape and soil characters for all the important crops including pigeon pea. Further, Naidu et al. (2003) attempted to establish the soil-site suitability criteria for pigeon pea, but seemed to have generalized and hence needs refinement in the light of the present findings.

\section{Conclusions}

The long term studies on yield contributing weather parameters of pigeon pea revealed that the moisture availability period as reflected by LGP is a critical factor deciding the growth and yield. Besides, rainfall distribution as indicated by rainy days, thermal requirement as indicated by GDD and the cumulative leaf area as measured by LAD are also the significant parameters in the decreasing order contributing for the growth and yield of pigeon pea. The relationships of above parameters with seed yield of pigeon pea have been quantified individually and in combination.

\section{References}

AICRPAM, (2013). Annual progress report, All India Coordinated Research Project on Agrometeorology, University of Agricultural Sciences, Gandhi Krishi Vignana Kendra Bengaluru, Karnataka.

Barrie, G., Wetherill, Duncombe, P., Kenward, M., Kollerstrom, J., Paul, S.R. and Vowden, B.J.
(1986). Regression Analysis with Applications, Chapman and Hall Publications, London, New York, p.311.

Higgins, G.M. and Kassam, A.K. (1981). FAO-agro ecological zone approach to determining of land potential. Pedologie 31, 147-168.

Naidu L.G.K., Rama murthy, U., Rajendra Hedge, Challa, O., Krishnan, P. and Gajbhiye, K.S. (2003). Soil site suitability criteria for major crops, NBSS \& LUPTechnical Report. No. 582.

Shivaramu, H.S., Yadav, S.C., Gaikawad, S.T., Raghumohan, N.G. and Srinivas, S. (1997). Land use requirements of sorghum on swell-shrink soils based on its performance at varied management. Journal of the Indian Society of Soil Science 45, 315-325.

Shivaramu, H.S. (2012). Soil suitability assessment for pigeon pea in alfisols of Karnataka- a modeling approach. Agropedology 22, 69-73.

Sys, Ir. C., Van Ranst, E., Debaveye, Ir. J. and Beernaert, F. (1993). Land Evaluation, Part 3 (crop requirements), Agricultural Publications -No. 7, International Training Centre for Post Graduate Soil Scientists, University Ghent,Belgium.p199.

University of Agricultural Sciences (2012).Package of cultivation practices for high yields, UAS pub. , Bangalore, pp 123-131.

Received : February, 2016

Accepted : June, 2016 